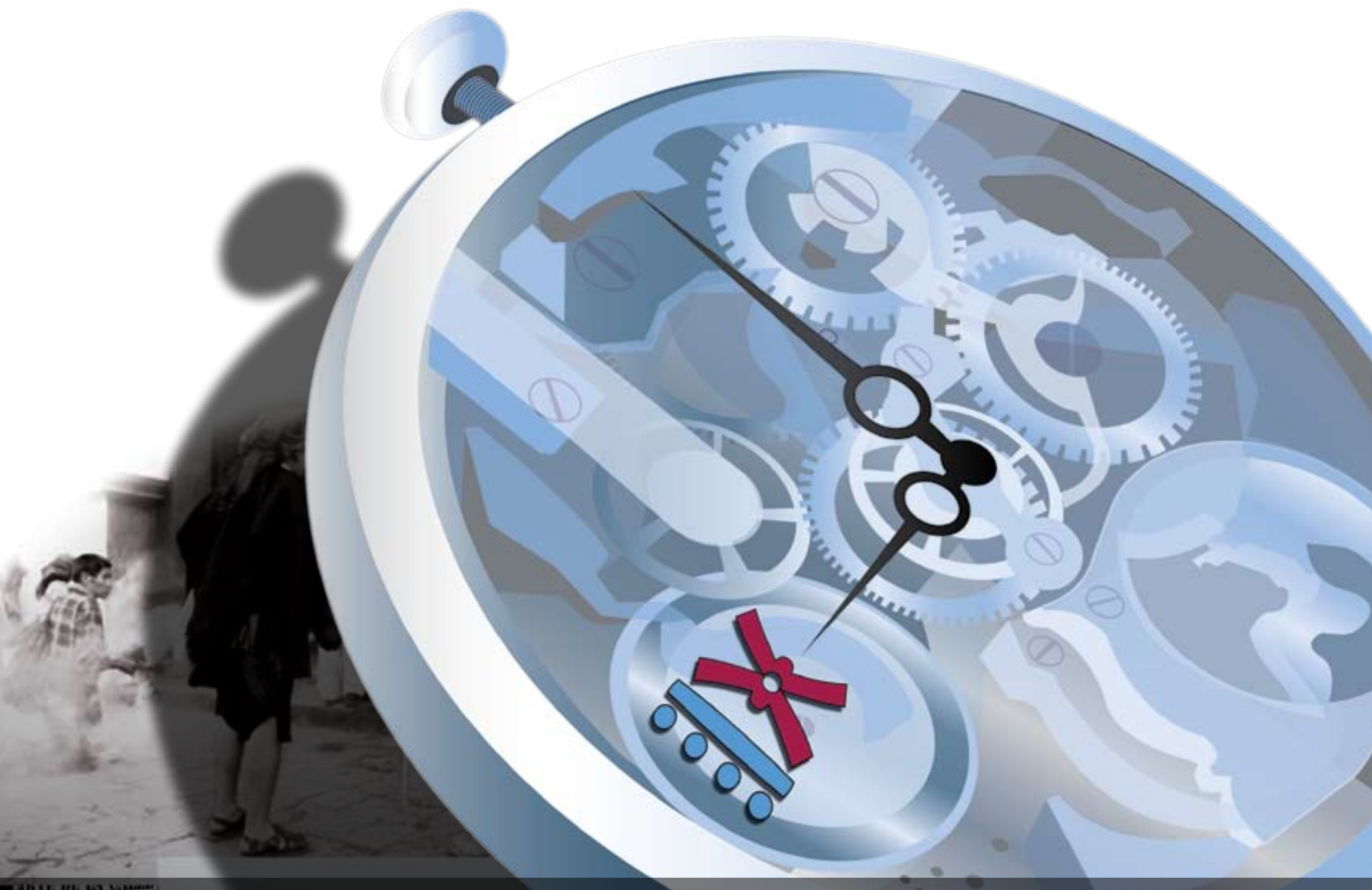

$9^{\circ}$ C O N G R E S O 2. CENTROAMERICANO DE H ISTO R I A

Universidad de Costa Rica

ISSN 1409- 469X

Fecha de recepción: 15 de mayo 2008 Fecha de aceptación: 30 de mayo 2008

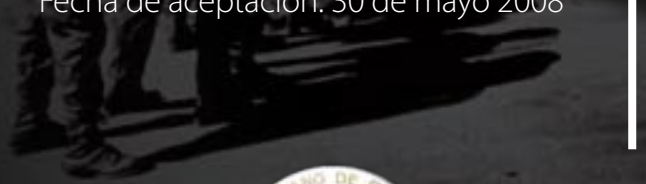

"Política exterior argentina e interés nacional: una mirada a Latinoamérica"

Miembros del Consejo Editorial:

Dr. Ronny Viales, Dr. Juan José Marín

Editores Técnicos:

Allan Fonseca, Andrés Cruz, Gabriela Soto
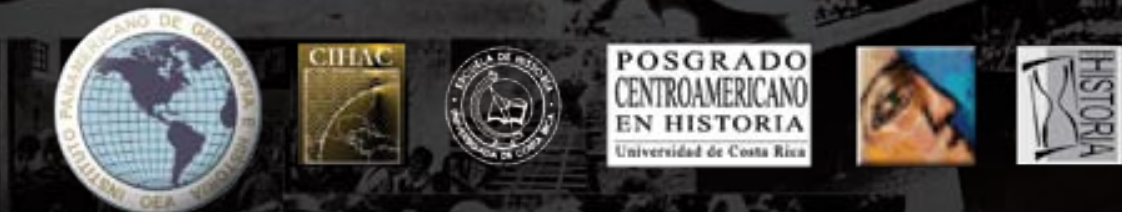
Indexaciones: Repositorio de Revistas UCR, DIALNET, Latindex, REDALYC Directorio y recolector de recursos digitales del Ministerio de Cultura de España, Directory of Open Access Journals. Diálogos Revista Electrónica de Historia ISSN 1409- 469X. Número especial 2008. Dirección web: http://historia.fcs.ucr.ac.cr/dialogos.htm

\title{
"Política exterior argentina e interés nacional: una mirada a Latinoamérica”
}

\author{
Melisa Deciancio
}

French 2881, $6^{\circ}$ B. Ciudad de Buenos Aires, (1425) Buenos Aires. Argentina (54 11) 4806 - 7897 mdeciancio@flacso.org.ar

FLACSO - Argentina

Fernanda López Franz

Conquista del Desierto 322. Ezeiza, (1804).

Buenos Aires. Argentina

(54 11) 4295 - 2077

fernandalopezfranz@gmail.com

Centro de Estudios Latinoamericanos - UNSaM 


\section{Introducción}

Pensar sobre la política exterior argentina nos conduce casi indefectiblemente a preguntarnos, como ya lo hicieron, e incluso cuestionaron, muchos autores, acerca de si existe realmente una política exterior argentina.

Hacia 1874, Domingo Faustino Sarmiento ya enunciaba que "la República Argentina ha carecido siempre de política exterior”. En la misma línea, en 1881 en ocasión del Tratado Argentino - Chileno, Nicolás Avellaneda sostenía que "nada hay tan inconsistente como nuestra política exterior”. En la misma línea, en 1914, en el recinto de la Cámara de Diputados, Estanislao Zeballos sostuvo que "La República Argentina, en materia internacional es la nación menos preparada del universo. Su pueblo, sus hombres públicos, sus universidades, sus escuelas, no se ocupan de estas cosas sino al pasar. Nunca hemos procurado ilustrarnos a fondo sobre esas altas cuestiones de Estado en tanto interesan al país, y hemos preferido la política interna de personalismos, de asuntos electorales y otras de mínima importancia. Nosotros no sabemos negociar, carecemos de carácter, y por eso temo a veces cuando se inicia un tratado internacional" (Muñiz, 1996)

Apoyados en la creencia acerca de la inexistencia de una política exterior argentina, muchos académicos recurrieron a rastrear tendencias o constantes en la actuación internacional del país que permitieran delimitar una caracterización de la misma de acuerdo a las evidencias empíricas. En este sentido, Ferrari (1981) señalan ciertas constantes que habían regido por décadas, esto es, el pacifismo, el aislacionismo, la evasión por medio del derecho, el moralismo, el enfrentamiento con Estados Unidos, el europeísmo y desmembramiento territorial. Por su parte, Puig (1975), marca como las grandes tendencias a la afiliación a la esfera de influencia británica, la oposición a Estados Unidos, el aislamiento respecto de América Latina y la debilidad de la política territorial (Muñiz, 1996). Ambas visiones coincidentes reflejan lo que se conoce como el Paradigma de “relaciones espaciales” con Gran Bretaña y Europa característico del período 1880-1914, donde la idea predominante consistía en ver a los países europeos, especialmente -pero no únicamentea Gran Bretaña, como socios comerciales, sin comprometerse demasiado políticamente.

A partir del surgimiento del Paradigma de "relaciones especiales" con Estados Unidos en la década del noventa es que comienza a manifestarse cierto consenso acerca de la existencia de una política exterior como política de gobierno, mucho más clara y manifiesta. A partir de entonces, 
y en los análisis posteriores sobre la situación de las relaciones internacionales argentinas, los debates comenzaron a girar en torno a la idea de "muerte" o no de la política exterior (Escudé, 2006; Palermo, 2006; Calle, 2006; Corbacho, 2006; Merke, 2006).

Mucho se ha debatido alrededor de esta cuestión, existen aquellos que dudan de la posibilidad de que los gobiernos argentinos desarrollen una política exterior coherente, caracterizándola como incongruente, esquizofrénica, y hasta inexistente. En este sentido, consideramos que las diversas características que ha ido adquiriendo la política exterior argentina no denotan más que una irregularidad, propia de cualquier nación que no posee una "política de Estado" en su relación con el exterior, sino que fluctúa de acuerdo a las diversas "políticas de gobierno" adoptadas. Con esto no nos referimos a una carencia de compromiso político ni a la falta de conocimiento de los gobernantes acerca de cómo llevar adelante la política exterior del país. La irregularidad de la que estamos hablando se relaciona más con cierta falta de linealidad, la cual, dependiendo de cómo se la mire, puede ser vista como incoherente o esquizofrénica, pero también como una mera adaptación del país a las condiciones cambiantes del contexto internacional en el modesto lugar que le ha tocado ocupar en la estructura del sistema mundial.

El objetivo del presente artículo es argumentar, en base al posicionamiento de Argentina frente a tres hechos históricos extremos ${ }^{1}$ ocurridos en Latinoamérica, la existencia de una política exterior propia, y a su vez demostrar que, al contrario de lo que se suele afirmar, Argentina no dejó de lado a América Latina de la misma, sino que en momentos clave estuvo presente, asumiendo un rol muy importante en el liderazgo de la región.

Coincidimos con quienes sostienen que el contexto internacional es esencial para comprender las motivaciones que provocan las decisiones políticas. Aunque en algunos casos puedan imponerse personalismos o ambiciones, en general ha prevalecido, aún en decisiones de política exterior controvertidas, la convicción de que con ellas se protegían necesidades reales del país (Muñiz, 1996).

Hemos escogido tres sucesos relevantes en el acontecer latinoamericano que comprenden la esfera política, la de seguridad y la económica (Revolución Cubana, el Grupo de Contadora y el Grupo de Cartagena, respectivamente), las cuales nos permiten demostrar que el accionar del gobierno en cada uno de los casos coincidió con la convicción por parte de sus actores de que era lo estratégicamente conveniente para la nación, demostrando con ello, la relevancia de América Latina en la diagramación de la política exterior argentina.

1 Nos referimos con casos extremos a aquellos sucesos en los que intereses vitales del continente estaban en juego y que marcaron un antes y un después en el modo de resolver o posicionarse frente a cambios en la coyuntura internacional. 
Los casos seleccionados cumplen con la característica particular de ser casos extremos. En este sentido, la búsqueda de un a accionar consensuado se convirtió en la mejor opción a seguir a fin de alcanzar el mejor resultado para el interés nacional. Cabe destacar que el posicionamiento marginal de los países de la región en la estructuración del sistema internacional hace que su poder de negociación aumente ampliamente si ésta se realiza en bloque.

Este trabajo se desarrolla en tres etapas centrales donde ampliaremos los casos seleccionados con el fin de demostrar, no sólo su relevancia para el continente, sino que, en cada uno de ellos Argentina participó activamente en el marco multilateral, con el objetivo de encontrar una solución conjunta a los problemas de la región que satisficieran sus intereses nacionales.

$\mathrm{Al}$ escoger los tres sucesos, es claro que estamos excluyendo otros de similar importancia, decidimos realizar nuestra selección con un criterio temático (seguridad, política y economía) y no un análisis cronológico (esto es, buscar como lo han hecho otros autores, lineamientos o constantes a través del tiempo), ya que consideramos que realizarlo de este modo, nos permite estudiar la política exterior argentina en todas sus facetas, esto es, de manera mas comprehensiva.

En primer lugar desarrollaremos el accionar argentino frente a un caso de la esfera política: la Revolución Cubana de 1962. Consideramos que los intentos del gobierno argentino de ese entonces por alcanzar una coordinación latinoamericana para mantener a Cuba dentro del sistema de la OEA, fueron cruciales

En segunda instancia, en la esfera de la seguridad, el análisis del Grupo de Contadora nos permite demostrar cómo, ante la intervención de una potencia externa en el continente en un contexto de enfrentamientos generalizados alrededor del mismo, el accionar consensuado de los países de la región logró que un grupo de países con menor poder específico en el sistema internacional lograra establecer los límites a esa intervención y, paralelamente, eliminar las rivalidades históricas entre ellos.

Finalmente, el estudio de la conformación del Grupo de Cartagena nos da la posibilidad de comprender cómo en un caso que afectó a la economía de la mayoría de los países de la región, la opción multilateral volvió a convertirse en el mejor camino hacia la defensa de los intereses nacionales.

Estos tres ejemplos marcan un antecedente en la búsqueda argentina de consenso regional para la solución de conflictos extremos. 


\section{La Revolución Cubana}

La Revolución Cubana significó un antes y un después en el accionar de los diferentes gobiernos latinoamericanos y su política exterior. Generó dudas acerca de la postura que debían adoptar los países, y el temor por parte de los Estados Unidos de que éste fuera el comienzo de una expansión comunista en su patio trasero. Tanto las grandes potencias como los países más chicos debieron readaptar su postura internacional de acuerdo a las nuevas condiciones.

En América Latina, la postura adoptada fue desde el principio ambivalente, debido a las presiones de Washington sobre los países de la región y las promesas de ayuda económica (materializada en la Alianza para el Progreso), a cambio de apoyo para aislar a Cuba y de demostrar la inefectividad del modelo planteado por el nuevo gobierno revolucionario.

En el caso argentino, si bien los presidentes Kennedy y Frondizi tuvieron coincidencias en el ámbito político y económico ${ }^{2}$, en el ámbito de la seguridad, la política estratégica anticomunista de la administración Kennedy no fue respaldada por el gobierno argentino.

Muchos latinoamericanos, temerosos de las consecuencias que la pobreza y la injusticia pudieran tener sobre el bienestar del país, se sentían atraídos por el modelo cubano como promesa de desarrollo; sin embargo, para Estados Unidos, Cuba había sido una víctima más del comunismo que debía combatirse antes de que lograra expandir sus raíces hacia el resto del continente. En este contexto, el presidente argentino tenía la firme intención de conformar un bloque sudamericano, que buscara disociarse de la crisis cubana. Había apoyado entusiastamente el proyecto de Kubitschek, Operación Panamericana ${ }^{3}$, donde entre otros puntos, se establecía la urgente necesidad de encarar programas de desarrollo en América Latina para la preservación de la democracia.

Lanús (1984), ve a la cuestión cubana como ejemplo y estigma a la vez. Ejemplo para los que veían en ella un camino hacia la realización de esperanzas que vivían postergadas por la dependencia política, por el sojuzgamiento de las poblaciones bajo minorías ávidas y crueles, por la pobreza, y el analfabetismo. Para otros, fue el estigma de la dominación del pueblo por un poder totalitario de inspiración comunista. En general, el gobierno de Frondizi, intentaría escapar a esas opciones desde el comienzo mismo de la cuestión cubana.

En oportunidad de la Reunión del Comité de los Veintiuno, en Buenos Aires en mayo de 1958, Frondizi intentó despolitizar la presencia de Fidel Castro definiendo a la Conferencia 
en términos económicos y paralelamente, aprovechó la ocasión para expresar a Castro su preocupación por evitar la violencia y la exportación de la Revolución al resto de América Latina.

Asimismo, la primera vez que el mecanismo de Consulta se puso en marcha por causas puramente americanas fue al año siguiente, durante la V Reunión de Ministros de Relaciones Exteriores cita en Santiago de Chile, cuyo fin era tratar la situación general del Caribe y robustecer el principio de no intervención y la vigencia de lo derechos humanos. En esta Reunión se aprobó por unanimidad la Declaración de Santiago, cuyo contenido incorporaba al sistema interamericano principios que incidían en el orden interno.

En Febrero de 1960 el Presidente Eisenhower viajó por primera vez a la Argentina, Brasil, Chile y Uruguay. El propósito real de esos viajes era sondear las opiniones sobre la posibilidad de implementar sanciones colectivas contra el gobierno de Cuba en el marco de la OEA. El gobierno norteamericano, se encontró con que el diagnóstico de los gobernantes sudamericanos era diferente: para éstos últimos, el problema cubano, era una cuestión bilateral que debía solucionarse entre Cuba y Estados Unidos, mientras que para Estados Unidos, era un caso de penetración comunista en el continente que debía resolverse de manera colectiva en el marco de la OEA.

A medida que el conflicto se agravaba cada vez más, el gobierno peruano solicitó a la OEA una reunión especial de Ministros de Relaciones Exteriores para tratar el caso cubano donde Argentina apoyó la propuesta de Perú.

Durante la Séptima Reunión de Consulta, que tenía como finalidad principal "enfrentar la amenaza extracontinental en América Latina y los actos de subversión comunista”, el delegado argentino Pablo Pardo, presentó un proyecto de resolución que proponía elaborar un Tratado que estableciera los derechos y obligaciones de los Estados en lucha contra el comunismo, y los métodos más idóneos para la prevención y erradicación del movimiento comunista en el continente, que no fue respaldado por el presidente Frondizi.

La resolución aprobada en esta Reunión, si bien condena enérgicamente la intervención o amenaza de intervención de una potencia extracontinental en los asuntos latinoamericanos, no menciona en su texto a Cuba. De este modo, la administración Eisenhower llegó a su final sin lograr una solución para la cuestión Cubana, a la vez que la mayoría de los gobiernos de la región fueron partidarios de la conciliación y de la búsqueda de un compromiso político entre Estados Unidos y Cuba, con el fin de evitar que el conflicto Este - Oeste se introdujera en la región. 
Hacia 1961, cuando la invasión a Bahía de los Cochinos por parte de los Estados Unidos era inminente, el presidente argentino se manifestó claramente en contra de la misma, considerándola una forma más de intervención en los asuntos internos de un Estado y una violación al principio de autodeterminación.

Durante este período el gobierno Argentino intentó oficiar en reiteradas oportunidades como árbitro entre Estados Unidos y Cuba, pero sus intenciones se vieron siempre frustradas debido a la negativa de ambos países a considerar la propuesta. La cancillería argentina informó de su iniciativa a ambos países, anunciando también la designación de dos embajadores para llevar adelante este fin ${ }^{4}$. La respuesta cubana fue clara: "el gobierno de Cuba cree que es lamentablemente inútil iniciar cualquier actuación al respecto mientras el gobierno de los Estados Unidos de Norteamérica no asuma una actitud propicia a negociar por la vía bilateral, en pie de igualdad y con agenda abierta, sus diferencias con el gobierno cubano, para cuya discusión reiteramos nuestra disposición favorable” (Altamirano, 1998). Del mismo modo, Washington rechazó también la iniciativa argentina argumentando que no se trataba de un diferendo entre Estados Unidos y Cuba, sino que el problema era hemisférico.

Este ofrecimiento de Argentina fue fuertemente criticado al interior de las Fuerzas Armadas debido a que para lo concepción de los militares argentinos de la época, toda posición que no fuera un apoyo decidido a los Estados Unidos era considerada una traición a los intereses nacionales y una colaboración con los extremistas.

Esta "política de puente aislado" característica de Frondizi, se centró en sus intentos de alcanzar consenso entre posturas opuestas, lo cual, no fue bien recibido a nivel doméstico, generando diversas presiones y enfrentamientos internos con las facciones militares. La visita clandestina de Ernesto Guevara a nuestro país el 18 de Agosto de 1961 puede verse como una continuación de este intento de hacer de árbitro entre Estados Unidos y Cuba. Aunque el encuentro fue preparado con el mayor sigilo, esto no impidió que llegara a oídos de las Fuerzas Armadas y se provocara entre ellas una gran conmoción. El presidente asumió toda la responsabilidad, aunque sin aclarar por qué la visita debió ocultarse incluso al gabinete militar. La visita de Guevara socavó aún más la base en la que se sustentaba el gobierno, introduciendo nuevas dudas y desconfianza.

Mientras tanto, la cada vez más estrecha relación entre Cuba y la URSS condujo a que $4 \quad$ En esa época trascendió que se trataba de Miguel Ángel Cárcano para Washington y Carlos M. Muñiz para La Habana. 
Estados Unidos siguiera impulsando la propuesta de convocar a una Reunión de Consulta de Ministros de Relaciones Exteriores para sancionar el régimen cubano. que finalmente fue convocada en Punta del Este para fines de Enero de 1962. Unos días antes de la reunión, Frondizi voló a Montevideo para reunirse con Haedo y declaró públicamente que "La Argentina mantiene el principio de no intervención y de autodeterminación de los pueblos" y que "permanecerá adherida a la filosofía occidental y cristiana proclamada en Uruguayana" (Altamirano, 1998).

Como mostraron los indicios anteriores a la Reunión, Frondizi no alineó a la Argentina con Estados Unidos, sino que la estrategia de la comitiva de la cancillería en Punta del Este -diseñada por el Subsecretario Oscar Camilión- adoptó como premisa principal que la Argentina no propugnaría sanciones contra Cuba debido a que:

a. No se quería romper con Cuba

b. Las sanciones violaban el principio de no intervención

c. Las mismas eran ineficaces, porque si lo que se quería era debilitar a Fidel Castro, se obtendría el resultado contrario, ya que la ruptura favorecería la satelización de Cuba dentro del bloque soviético.

Este último punto concuerda con lo que sostiene el ex canciller Florit (1996), en cuanto a que se consideró la necesidad de mantener a Cuba dentro de sistema para evitar la profundización de su dependencia respecto a la Unión Soviética. Tal fue el sentido del voto argentino en la conferencia de Punta del Este. Finalmente, la votación respecto de la exclusión de Cuba de la OEA fue de catorce votos a favor, uno en contra y seis abstenciones (Argentina, Brasil, Bolivia, Chile, Ecuador y México, el llamado grupo de los seis).

La abstención implicó serias consecuencias internas para el gobierno de Frondizi, especialmente por parte de las Fuerzas Armadas, preocupadas por la expansión del comunismo en América Latina y, sobre todo, en la Argentina. A pesar de ello, en un discurso promulgado en Paraná semanas más tarde, el presidente radical defendió su posición: “... Lo que se está discutiendo en América no es la suerte de un caudillo extremista que se expresa a favor de un orden político que nada tiene que ver con la realidad de nuestros pueblos, sino el futuro de un grupo de naciones subdesarrolladas que han decidido libremente ascender a niveles más altos de desenvolvimiento económico y social. Si esa soberana decisión no es respetada; 
si se la pretende ocultar o distorsionar con el juego ideológico de los extremismos, entonces sí que el mal será difícil de conjurar: un continente entero se convulsionará política y socialmente" (Discurso de Paraná, 1962).

Finalmente, como consecuencia de lo inevitable, bajo una fuerte presión interna, el gobierno argentino rompió relaciones con Cuba el 8 de Febrero de 1962. Pocas semanas después un golpe de Estado derrocó al Presidente.

¿Qué explica la insistencia argentina en tratar de mediar entre Cuba y Estados Unidos aunque los síntomas de descontento del país del norte e internos se acentuaran?

Para el gobierno de Frondizi, Cuba era víctima del subdesarrollo, el cual era una de sus principales preocupaciones, y el causante de la expansión del comunismo en la región ${ }^{5}$. Es en este sentido que el Presidente recurrió a diferentes estrategias para intentar aunar esfuerzos con otros países del continente, a modo de mantener a Cuba dentro del sistema, apoyándolo explícita o tácitamente frente a los intentos de expulsarla del sistema interamericano.

La posición del gobierno argentino frente a lo acontecido en Cuba es un ejemplo de la mirada de la política exterior nacional hacia Latinoamérica y sus problemas, y una toma de posición clara y sólida frente a los mismos. A su vez, cristaliza el temprano esfuerzo del gobierno argentino por propiciar acciones conjuntas con países de la región, especialmente con Brasil, -más allá del éxito relativo de los resultados - a los fines de coordinar políticas con el resto de Latinoamérica. La búsqueda del gobierno argentino de alcanzar un mayor consenso en el ámbito regional, en una época donde el multilateralismo no era moneda corriente, sentó un precedente para hechos posteriores en los que la coordinación y el accionar consensuado fueron necesarios.

En la próxima etapa, desarrollaremos un caso propio de la esfera de seguridad que, aunque 20 años más tarde, demuestra una vez más la tendencia descripta.

\section{El grupo de Contadora}

El Grupo de Contadora, se dio en un contexto completamente distinto al del caso cubano. La llegada de la democracia, y casualmente, de un gobierno de la misma tendencia política que el de los años ' 60 , concluyó en una redefinición de la política exterior, marcando nuevamente la participación argentina en el intento de resolver de manera multilateral, un caso extremo que afectaba a la región.

5 En su gira por Europa Occidental calificó a América Latina como "la única zona deficientemente desarrollada en Occidente”. 
Hace 20 años atrás, los líderes latinoamericanos se congregaron con el objetivo de buscar la pacificación de América Central y, en particular, la finalización de las guerras civiles de El Salvador y Guatemala, y del enfrentamiento entre Nicaragua y Estados Unidos.

En enero de 1983, los cancilleres de Colombia, México, Panamá y Venezuela se reunieron en la isla de Contadora, con el propósito de plantear una iniciativa de paz conjunta para el conflicto centroamericano, dando lugar al Grupo de Contadora.

Los gobiernos de Contadora y del Grupo de apoyo a Contadora vieron en las políticas norteamericanas hacia Centroamérica una amenaza potencial a su propia seguridad, dado a que éstas abrían la posibilidad a una confrontación militar que inevitablemente tendría un impacto directo en los países vecinos. De esta manera, al tratar de influir en las acciones de los Estados Unidos mediante la creación de alternativas diferentes y viables constituyó uno de los aspectos cruciales de los esfuerzos de Contadora. Además, desde la perspectiva de estos países, las políticas norteamericanas parecían no sólo peligrosas sino además carentes de utilidad alguna (Rico, 1990).

En su visita a Lima en junio de 1985, el presidente argentino Raúl Alfonsín se reunió con el presidente electo Alan García, con quien analizó el problema del endeudamiento externo y la situación de Nicaragua. Ambos presidentes coincidieron en la necesidad de promover un orden internacional más justo y la conveniencia de impulsar acciones coordinadas de los países de la región para obtener mejor respuesta a sus reclamos (Escudé, 2000). Poco después, los cancilleres de Argentina, de Brasil, y de Uruguay se reunieron en Punta del Este con el objeto de analizar la situación de Centroamérica y los temas referidos a la posición económicofinanciera del continente. Como consecuencia de este encuentro, los tres países coincidieron en apoyar la posición del Grupo de Contadora. Al respecto, el entonces Subsecretario para Asuntos Latinoamericanos del gobierno argentino, Raúl Aleonada Sempé, sostuvo que "no convalidamos ningún caso de intervención de ningún país ni de injerencia en los asuntos internos de terceros países (...) Uno de los casos más graves de violación del principio de no intervención fue el caso de nicaragua. Unos años antes de que asumiéramos se había constituido el Grupo de Contadora a los fines de procurar una solución latinoamericana al conflicto centroamericano. El gobierno argentino, desde un principio, se interesó en respaldar activamente estos esfuerzos y cuando se hizo necesario, pues la presión de Estados Unidos era directa a través del apoyo político y económico a los “contras” (Aleonada Sempé, 1996). 
Fue así que, los gobiernos de la Argentina, Brasil, Perú y Uruguay anunciaron en forma conjunta su voluntad de ponerse "a disposición del Grupo de Contadora para las consultas sobre aquellas cuestiones en las que puedan prestar colaboración” (en Escudé, 2000), dando origen de este modo el Grupo de Apoyo a Contadora.

La Primera Reunión Conjunta de Contadora y el Grupo de Apoyo -denominado el Grupo de los Ocho- se realizó en Cartagena de Indias, Colombia, donde se establecieron las bases y objetivos la misma, tales como "la decisión de fortalecer, con acciones concretas y con una firme unidad regional, el esfuerzo de negociaciones diplomáticas que ha promovido el Grupo de Contadora" y el riesgo de que el conflicto en Centroamérica "de no encontrar una solución pacífica y negociada, afectará la estabilidad política y social del conjunto de la América Latina" (Comunicado de los ministros de Relaciones Exteriores del Grupo de Contadora y del Grupo de Apoyo a Contadora, Cartagena, 25 de agosto de 1985).

Como señala Hirst (1990), gracias a la "potencialidad” que la acción de Contadora y el Grupo de apoyo había otorgado a sus participantes, el Grupo de los Ocho partió del convencimiento de que la capacidad que habían demostrado para actuar en la contención del conflicto y la propuesta de mecanismos de paz para la cuestión centroamericana podía ser utilizada para imaginar soluciones a otras problemáticas latinoamericanas.

Producto de la Segunda Reunión del Grupo, se acordó el llamado Mensaje de Caraballeda para la paz, la seguridad y la democracia en América Central, que consideraba el principio de la simultaneidad de las acciones de pacificación como un "requisito indispensable para alcanzar la paz" en la conflictiva región centroamericana. Planteando además, la necesidad de poner fin al apoyo externo a las facciones en lucha en el área; disminuir de forma programada la adquisición de armamentos; suspender las maniobras militares; y reducir progresivamente, hasta su completa eliminación, los asesores militares e instalaciones extranjeras en el área en conflicto. Además, se propició la firma de un compromiso de no agresión entre los cinco países centroamericanos; y la necesidad de adoptar medidas de reconciliación nacional en todos los casos de profundos conflictos facciosos internos, y priorizar el respeto a los derechos humanos y las libertades civiles.

Fue así como los gobiernos de México, Venezuela, Panamá, Colombia, Brasil, Argentina, Perú y Uruguay suscribieron la "Declaración de Río de Janeiro”, en la búsqueda de mayor proyección regional e internacional en su iniciativa de paz impulsada en los comienzos, que señala que "el 
surgimiento de la democracia en América Latina permite un intenso diálogo político en el que se reafirma la necesidad de conjugar esfuerzos y capacidades para encontrar soluciones propias a nuestras dificultades e impulsar el desarrollo independiente y sostenido en la región, nos une el propósito de fortalecer la democracia a partir de un vigoroso desarrollo económico y social de nuestra región, basado en un creciente proceso de cooperación e integración en América Latina"

Con la llegada de la democracia al resto de los países latinoamericanos, en 1990, Chile, Ecuador, Bolivia y Paraguay se unieron al grupo, el cual pasó a llamarse definitivamente "Grupo de Río".

El Grupo de Río se rearticuló como proyecto regional latinoamericano y caribeño por sobre las diferencias de los proyectos subregionales que establecen divisiones internas, en especial entre América Latina del Norte y Sudamérica. El grupo responde a la necesidad de estructurar -en lo político y lo estratégico- una visión compartida, no competitiva entre las subregiones; complementaria, de modo que supere las diferencias en un proyecto más amplio de concertación e interlocución, y que otorgue relevancia al conjunto de la región, en un momento histórico en el que ésta posee un menor peso en el mundo (Rojas Aravena, 2007).

La creación del grupo de Contadora, hace 20 años atrás, fue una iniciativa puramente latinoamericana que implicó una clara toma de posición de los países de la región frente a una cuestión que los afectaba directamente y que podría generarles implicancias futuras. De este modo, la participación argentina en este proyecto, demuestra una vez más el compromiso del país con la situación latinoamericana, ya sea por mero interés individual o por la lucha hacia una "causa justa”, la cancillería no se mantuvo al margen de los acontecimientos, participando activamente de los intentos por resolver el conflicto; mas "no sólo se trató de la defensa pasiva [del principio de no intervención] sino que participamos e impulsamos iniciativas diplomáticas para garantizar su efectivo cumplimiento (...)así ante el peligro de una intervención mayor que traería la guerra y la violencia a todo América Latina, constituimos el Grupo de Apoyo a Contadora, junto con Brasil, Perú y Uruguay” (Alconada Sempé, 1996).

El Grupo de Contadora puede ser visto como un ejemplo más de un intento frustrado de los países latinoamericanos en su resistencia a la presencia de Estados Unidos en la región, o puede ser visto, en cambio, como la demostración de que los países del continente pueden actuar 6 Declaración de los jefes de Estado y de Gobierno del Mecanismo Permanente de Consulta y Concertación Política de América Latina y el Caribe, Declaración de Río de Janeiro, Río de Janeiro, Brasil, 18 de diciembre de 1986 
conjuntamente para promover la estabilidad del mismo, marcando un antes y un después en la forma de solucionar los problemas que afectan a América Latina.

El Grupo significó, además, el fin de la hipótesis de conflicto entre estos países, que había reinado desde la formación de los Estados-Nación en la región. Este viraje fue de vital importancia para su estabilidad futura, que permitió la continuidad del proyecto, con cada vez más adhesiones, pero transformado en el nuevo Grupo de Río, que comprendiendo a la mayor parte de los países latinoamericanos ${ }^{7}$ continúa con el objetivo de pacificación de la región por sobre los nuevos problemas que la hostigan como la pobreza, la desocupación, el crimen organizado, los problemas de gobernabilidad, etc.

La creación de un ámbito multilateral para la resolución de cuestiones ligadas a la seguridad en el continente no debe pasarse por alto. Aunque dada en un contexto mucho más propicio a la posibilidad de una acción consensuada, este grupo marcó el comienzo del multilateralismo institucionalizado en la región -entendemos con esto, la búsqueda de acción conjunta mediante la firma de acuerdos formales entre países- eliminando la percepción de amenaza entre los países, convirtiéndolos de "enemigos a amigos”, y permitiendo un mayor entendimiento futuro para la búsqueda de soluciones coordinadas en otras esferas afectadas.

\section{El Grupo de Cartagena}

El último caso a desarrollar se centra en la esfera económica de análisis, donde Argentina buscó, una vez más, satisfacer sus intereses nacionales a través de la participación en la negociación multilateral.

“El 20 de agosto de 1982, después de haber reembolsado sumas considerables en el curso de los primeros siete meses del año, el gobierno mexicano declaró que el país no estaba en condiciones de continuar los pagos, y decretó una moratoria de seis meses” (Toussaint, 2004). Como ya es sabido, la crisis de la deuda mexicana de 1982 se extendió a la mayoría de los países de América Latina, afectándolos severamente. Como señala Diana Tussie, en un primer momento, la crisis tomó a todos por sorpresa y cada deudor luchó sólo para mantenerse a flote (Tussie, 1988).

En este contexto, la intención inicial del gobierno argentino fue la de conformar un pool $7 \quad$ Países y bloques integrantes (por orden de admisión): Argentina (1986), Brasil (1986), Colombia (1986), México (1986), Panamá (1986), Perú (1986), Uruguay (1986), Venezuela (1986), Chile (1990), Ecuador (1990), Bolivia (1990), Paraguay (1990), CARICOM (1990), Centroamérica (1990-1999), Costa Rica (2000), El Salvador (2000), Guatemala (2000), Honduras (2000), Nicaragua (2000) y República Dominicana (2000). 
o cartel de países deudores para encontrar una solución multilateral al problema de la deuda externa. Fue así, como se proyectó una reunión inicial en Quito; Brasil, México, Colombia y Argentina se congregaron para encontrar una salida conjunta a la crisis generalizada de la región, instando a la integración latinoamericana.

La declaración de Quito establecía la posición de los países de América Latina, quienes advirtieron a los países desarrollados que no podrían garantizar el pago de la deuda externa si los acreedores no adoptaban: “(...) criterios flexibles y realistas para la renegociación de la deuda, incluyendo plazos, períodos de gracia y tasas de interés compatibles con la recuperación del crecimiento económico. Sólo de esta forma podrá garantizarse la continuidad en el cumplimiento del servicio de la deuda (...)”. Llamando a los dirigentes de estos países a reconocer: “(...) la gravedad de la situación económica de la región, su alto costo social y la necesidad de participar urgentemente en medidas que permitan enfrentar la crisis, directamente a través de sus gobiernos y de los organismos internacionales” (citado por Escudé, 2000).

Como resultado de la reunión de Quito se acordó un plan de acción, solicitando períodos de repago a más largo plazo, el no incremento del costo de la deuda como resultado de la refinanciación y el establecimiento de un nexo entre el servicio de la deuda y los ingresos por exportación. Si bien la reunión no tuvo resultados espectaculares, sirvió al menos para cambiar los términos de la discusión pasando de la acotada perspectiva técnica y financiera, seguida hasta entonces, a las implicancias de neto corte sociopolítico. "Los presidentes y cancilleres reunidos en la capital ecuatoriana comunicaban un mensaje: La deuda era una cuestión política” (Roett, 1985, en Tussie, 1988).

En una segunda instancia, la cancillería del gobierno radical promovió, en forma conjunta con Brasil, Colombia y México, la convocatoria a una reunión de cancilleres y ministros de Economía de los países más endeudados, con el objeto de adoptar medidas concretas orientadas a obtener cambios en la política financiera y comercial internacional favorables a los intereses de estos países.

Con la incorporación de Ecuador, Perú y Venezuela, se elaboró un documento conjunto que fue presentado ante el Grupo de los 7 reunido en Londres, reclamando a los acreedores alcanzar un diálogo constructivo entre las partes para aliviar las cargas de la deuda, las cuales consideraban imposibles de resolver por los medios propuestos por los organismos de crédito y los bancos. El reclamo no produjo ningún cambio en la opinión de los países desarrollados, que 
seguían abogando por una resolución bilateral del problema y siguiendo las recetas de austeridad propuestas por los organismos.

Esta iniciativa se encontró con la limitación de la diversidad de intereses de los miembros, y su falta de compromiso con la postura reivindicatoria del gobierno argentino. Países como México y Brasil prefirieron recurrir a mecanismos tradicionales, como la negociación bilateral. El documento final de la reunión, denominado Consenso de Cartagena, concluyó en la creación de un mecanismo de consulta y seguimiento regional, con el objetivo de ayudar a la concreción de encuentros con los países acreedores.

Debido a la falta de apoyo de los demás países latinoamericanos a la propuesta argentina, el gobierno radical debió adoptar el camino bilateral propuesto por los gobiernos y bancos acreedores.

A fines de mayo de 1987 funcionarios de los países miembros del Grupo de Cartagena se reunieron en México con el objeto de elaborar directrices para solucionar la crisis de la deuda. Como producto de esta reunión, a principios de junio los países integrantes del Consenso de Cartagena solicitaron al Grupo de los Siete que asumieran la responsabilidad de encontrar soluciones de fondo al problema del endeudamiento externo, eliminaran las prácticas proteccionistas y los factores que obstaculizaran la recuperación económica de los países en vías de desarrollo (Escudé, 2000).

Una vez más, el Consenso de Cartagena demuestra el intento argentino de alcanzar la satisfacción de sus intereses nacionales a través de un mejor posicionamiento negociador frente a los organismos internacionales al actuar conjuntamente con los países de la región. La iniciativa de encarar una negociación multilateral para subsanar el problema de la deuda externa pone en evidencia la presencia del país en las cuestiones que afectan al continente. A pesar de no haber sido exitosa en última instancia, fue una forma más de encarar un proyecto conjunto en el que Argentina demostró la relevancia que otorga al accionar multilateral latinoamericano

La falta de apoyo por los demás países puede ser vista como el fiel reflejo del peso estratégico con el que cuentan los países más poderosos - específicamente Estados Unidos- en las decisiones de los gobiernos de la región, donde los temores a posibles represalias prevalecen sobre las necesidades de desarrollo. 


\section{Conclusiones}

Frente a los casos analizados, podemos afirmar, retomando nuestra pregunta inicial acerca de si hubo históricamente una política exterior argentina hacia América Latina, que efectivamente ésta existió.

Consideramos que no sólo han existido, sino que todavía, y aún más claramente hoy en día, perduran lineamientos claros de política exterior argentina de cara al continente, que, dependiendo de las diferentes coyunturas internacionales, se han enfocado hacia la satisfacción de lo que se consideraba el interés nacional. Al contrario de lo que se ha sostenido por largo tiempo, en momentos críticos del acontecer de la región, Argentina ha optado por seguir una política exterior más cercana al latinoamericanismo, acorde con el accionar del resto de los países del continente, ya sea apoyando iniciativas de otros países, o bien dando el primer paso e intentando liderar las coaliciones.

La participación Argentina en la toma de posición del continente frente a la Revolución Cubana es uno de los ejemplos de esta política. La adhesión y defensa del derecho de autodeterminación del pueblo cubano y el principio de no intervención y el reclamo por mayor compromiso con los países en desarrollo, reflejan la preocupación del país por los problemas de desarrollo de la región y la insistencia en el respeto a los derechos fundamentales de los países más débiles del sistema internacional como única defensa frente a las intromisiones externas. Si bien Frondizi no logró conformar un verdadero bloque de acción conjunta, como es el caso de los otros dos hechos estudiados, identificamos la firme intención de hallar consenso para su accionar entre el resto de los países latinoamericanos y buscar la mejor manera de que la cuestión cubana sea resuelta a través de los mecanismos que los países de la región consideren mejor para la misma.

Tanto el segundo como el tercer caso planteado muestran la capacidad del gobierno argentino, en épocas históricas diferentes y con mayor o menor perdurabilidad, de formar coaliciones con la finalidad de proteger sus propios intereses y los de la región.

Como miembro del Grupo de Apoyo a Contadora, y el posterior Grupo de los Ocho, Argentina participó activamente en la defensa del principio de autodeterminación de los pueblos demostrando su habilidad e interés por encontrar soluciones "latinoamericanas" a los conflictos regionales. Es posible discutir el éxito que ha tenido este intento por resolver la crisis en Centroamérica, pero no se puede poner en duda la relevancia que ha tenido que por primera vez en su historia, los países del continente decidan resolver las cuestiones de seguridad que los conciernen dejando 
de lado los intereses de Estados Unidos y tratando de imponer límites a su accionar. Desde una perspectiva del conflicto en sí, Contadora puede ser visto como un fracaso, pero desde el punto de vista de la integración -aunque más no sea, informal- implicó un avance significativo para el multilateralismo regional.

De la misma forma, el Grupo de Cartagena cristalizó la búsqueda de una salida multilateral latinoamericana al problema de la deuda externa, que afectaba la estabilidad económica de los países. Esta vez, la posición argentina fue más firme y sostenida. A pesar del fracaso final de las deliberaciones, desde el principio Argentina insistió en la conveniencia de recurrir a la negociación conjunta de la deuda, hasta el punto tal de llegar a perder el apoyo recibido por los demás países, desatando la disolución final del grupo debido, entre otras cosas, a las presiones de los Estados Unidos, cuya estrategia resultó más tentadora y menos costosa políticamente para los países latinoamericanos. Por la misma razón señalada respecto de Contadora, el grupo puede ser visto como un fracaso por no haber alcanzado los objetivos centrales por los que se formó, pero no deja de adquirir gran relevancia debido a su propia naturaleza multilateral de carácter puramente regional.

En los tres casos estudiados, Argentina actuó de modo coherente con lo que consideraba acorde al interés nacional. Procuró actuar de manera conjunta con los países de la región, ya sea para oponerse a la intervención y aislamiento de Cuba, como para evitar la intervención de una potencia en el continente o para fortalecer su poder de negociación frente a los organismos internacionales. Lo más importante a resaltar es que, en los tres casos, se consideró que actuar conjunta e integradamente era la mejor opción para la Argentina y la región, y que la opción multilateral constituía un marco de acción propicio para la defensa de sus intereses nacionales.

Revisar el pasado para analizar el presente es un ejercicio siempre fructuoso y enriquecedor, para pensar el futuro.

Hoy en día podemos ver que los casos desarrollados fueron de gran relevancia para generar un acercamiento mucho mayor entre los países latinoamericanos. Actualmente, la participación conjunta ya no se limita a casos extremos como los descriptos, sino que los ámbitos donde la búsqueda de consenso y cooperación tiene lugar, son cada más mayores.

En este sentido tal vez sea el momento de que la política exterior argentina hacia Latinoamérica se consolide y no sean sólo hechos aislados los que generen cooperación e integración. Reforzar esta tendencia permitiría generar previsibilidad y credibilidad entre los países de la región, 
contribuyendo a la diagramación de políticas a largo plazo, que otorguen la posibilidad de cooperar regionalmente para la resolución de problemas que nos afectan estructuralmente, como son la pobreza, la falta de credibilidad, la baja participación en la política como eficaz canalizadora de demandas, las falencias de los sistemas educativos y de salud, y la debilidad de las instituciones y del sistema democrático.

\section{Bibliografía}

- “Reclamaciones de América Latina”, La Nación, 14 de enero de 1984, p. 1, y “Aprobaron en Quito un extenso programa de reactivación económica”, La Prensa, 14 de enero de 1984, p. 1., en Escudé, C. \& Cisneros, A. (2000) Historia General de la Política Exterior de la República Argentina, disponible en http://www.cema.edu.ar/ceieg/arg-rree/historia. $\underline{\mathrm{htm}}$

- Altamirano, C.; Los nombres del Poder. Arturo Frondizi, Fondo de Cultura Económica, Buenos Aires, 1998

- Comunicado de los ministros de Relaciones Exteriores del Grupo de Contadora y del Grupo de Apoyo a Contadora, Cartagena, 25 de agosto de 1985, documento No 2948, FLACSO, en Escudé, C. \& Cisneros, A. (2000) Historia General de la Política Exterior de la República Argentina, disponible en http://www.cema.edu.ar/ceieg/arg-rree/historia. $\underline{\mathrm{htm}}$

- Comunicado de los ministros de Relaciones Exteriores del Grupo de Contadora y del Grupo de Apoyo a Contadora, Cartagena, 25 de agosto de 1985, documento No 2948, FLACSO

- Conil Paz, A. \& Ferrari, G. (1964) Política Exterior Argentina. 1930-1962, Buenos Aires: Huemul. 
- Corbacho, A. (2006) “En búsqueda de una política exterior inteligente”; Calle, F. (2006) "La crisis de gobernabilidad inconclusa en la Argentina y su impacto en las agendas interna y externa”; y Merke, F. (2006) "Hans J. Morgenthau en Gualeguaychú: una evaluación realista del conflicto por las papeleras", en Boletín del ISIAE, año 9, número 41, diciembre, pp. 1-2; 3-4; 5; 6-7; y 8-9, respectivamente, disponible en www.cari.org. $\underline{\mathrm{ar}}$

- Declaración de los jefes de Estado y de Gobierno del Mecanismo Permanente de Consulta y Concertación Política de América Latina y el Caribe, Declaración de Río de Janeiro, Río de Janeiro, Brasil, 18 de diciembre de 1986

- Escudé, C. \& Cisneros, A. (2000) Historia General de la Política Exterior de la República Argentina, disponible en http://www.cema.edu.ar/ceieg/arg-rree/historia.htm

- Escudé, C. (2006) "El conflicto de las papeleras y la muerte de la política exterior", Boletín del ISIAE, año 9, número 40, octubre, pp. 3-4, disponible en www.cari.org.ar

- Ferrari, G.; Esquema de la política exterior argentina, Buenos Aires: Eudeba, 1981.

- Florit, C. (1996) "Perfil internacional de un mundo en cambio, 1958-1962”, en La política exterior argentina y sus protagonistas 1880 - 1995, Silvia Ruth Jalaba (Comp.), Buenos Aires: Nuevo Hacer/GEL/CARI. 391 pp.

- Hirst, M. (1990) "Las iniciativas latinoamericanas de concertación: su influencia sobre las condiciones de paz en la región”, en Hirst, M., Paradiso, J., Pérez Llana, C., Rico F., C., Russell, R. y Tokatlián, J. G., Desarme y desarrollo en América Latina, Fundación Arturo Illia para la Democracia y la Paz.

- Lanús, A.; De Chapultepec al Beagle: Política Exterior Argentina 1945 - 1980, EMECE, Buenos Aires, 1984.

- Muñiz, C. M. (1996) en La política exterior argentina y sus protagonistas 1880 - 1995, Silvia Ruth Jalabe (Comp.), Buenos Aires: Nuevo Hacer/GEL/CARI. 391 pp.

- Palermo, V. (2006) “La política exterior argentina”, en Escenarios Alternativos, Año 4, $\mathrm{N}^{\mathrm{o}} 46$, Octubre.

- Puig, J.C.; La política Exterior Argentina y sus tendencias profundas, en revista Argentina de Relaciones Internacionales, $n^{\circ}$ 1, Buenos Aires, 1975 
- Rapoport, M. (2003) Historia económica, política y social de la Argentina (1880-2000), Buenos Aires: Ediciones Macchi.

- Rico F, C. (1990), "La experiencia de Contadora y el futuro potencial de una acción latinoamericana conjunta en asuntos de seguridad”, en Hirst, M., Paradiso, J., Pérez Llana, C., Rico F., C., Russell, R. y Tokatlián, J. G., Desarme y desarrollo en América Latina, Fundación Arturo Illia para la Democracia y la Paz.

- Rojas Aravena, F. (2007) "20 años del Grupo de Río: Renovando las oportunidades de concertación regional” disponible en www.fundacioncarolina.es

- Telegramade la Embajada argentina en Lima al subsecretariodeAsuntos Latinoamericanos, 30 de julio de 1985, en A. Frohmann, Puentes sobre la turbulencia, op. cit., p. 47 citado en Escudé, C. \& Cisneros, A. (2000) Historia General de la Política Exterior de la República Argentina, disponible en http://www.cema.edu.ar/ceieg/arg-rree/historia.htm

- Tussie, D. (1988) “La coordinación de los deudores latinoamericanos: ¿Cuál es la lógica de su accionar?”, Desarrollo Económico, Vol 28 № 109.

\section{Datos de las aUtoras:}

Melisa A. Deciancio (29796297) es Licenciada en Ciencia Política con orientación en Relaciones Internacionales de la Universidad de Buenos Aires. Actualmente se encuentra realizando la Maestría en Relaciones y Negociaciones Internacionales en FLACSO, Argentina, es coordinadora del Grupo de Jóvenes Pasantes del Centro de Estudios Estratégicos de la Armada Argentina y es Investigadora Asistente en FLACSO.

Fernanda B. López Franz (30020350) es Licenciada en Ciencia Política con orientación en Política Latinoamericana, por la Universidad de Buenos Aires. Actualmente cursa la Maestría en Estudios Latinoamericanos, en el Centro de Estudios Latinoamericanos de la Universidad Nacional de San Martín, por lo cual es becaria del Ministerio de Educación de la Nación. Ha trabajado en la Fundación Poder Ciudadano, y actualmente se desempeña como asesora en la Cámara de Diputados de la Nación Argentina y como Tutora del Curso Todos Somos MERCOSUR, convocada por la Cancillería Argentina y Consejo Consultivo para la Sociedad Civil. 